\title{
Louis-Sebastien Mercier, Les Tombeaux de Vérone (Giulietta e Romeo)
}

\section{Claudio Vinti}

\section{(2) OpenEdition}

1 Journals

\section{Edizione digitale}

URL: http://journals.openedition.org/studifrancesi/27648

DOI: 10.4000/studifrancesi.27648

ISSN: 2421-5856

\section{Editore}

Rosenberg \& Sellier

\section{Edizione cartacea}

Data di pubblicazione: 31 décembre 2006

Paginazione: 609-610

ISSN: 0039-2944

\section{Notizia bibliografica digitale}

Claudio Vinti, «Louis-Sebastien Mercier, Les Tombeaux de Vérone (Giulietta e Romeo) », Studi Francesi [Online], 150 (L | III) | 2006, online dal 30 novembre 2015, consultato il 08 novembre 2020. URL : http:// journals.openedition.org/studifrancesi/27648; DOI : https://doi.org/10.4000/studifrancesi.27648

Questo documento è stato generato automaticamente il 8 novembre 2020.

\section{(c) $(1) \&$}

Studi Francesi è distribuita con Licenza Creative Commons Attribuzione - Non commerciale - Non opere derivate 4.0 Internazionale. 


\title{
Louis-Sebastien Mercier, Les Tombeaux de Vérone (Giulietta e Romeo)
}

\author{
Claudio Vinti
}

\section{NOTIZIA}

LOUIS-SEBASTIEN MERCIER, Les Tombeaux de Vérone (Giulietta e Romeo). Introduzione, traduzione e note di Pierluigi LIGAS, Verona, Libreria Editrice Universitaria, 2005, pp.

471.

1 Questo ponderoso volume di Pierluigi Ligas è dedicato a un dramma settecentesco di un autore poco conosciuto, solo da pochi anni riabilitato dalla critica internazionale: Louis-Sébastien Mercier. I Tombeaux de Vérone sono l'ennesima versione teatrale ispirata dalle tragiche vicende di Romeo e Giulietta che il genio di Shakespeare ha reso immortali. In questo lavoro che coniuga ricerca ed erudizione, l'A. mette a frutto le sue conoscenze delle problematiche relative alla storia e alla teoria della traduzione, non disdegnando di affrontare coraggiosamente in prima persona la stessa traduzione dei Tombeaux, con l'obiettivo di «far sì che il lettore avverta il meno possibile che ciò che sta leggendo è stato in precedenza prodotto per qualcuno di lingua, cultura e pensiero diversi dai suoi».

2 Questa ricca pubblicazione della Libreria Universitaria di Verona si compone di tre parti principali: una lunga introduzione, in cui Ligas dà conto dei rapporti tra Mercier e il teatro del XVIII secolo, con una particolare attenzione rivolta alle vicende del dramma borghese; un importante studio sui Tombeaux de Vérone, mirato essenzialmente ad analizzare le scelte grammaticali, i personaggi e la lingua della pièce di Mercier; una terza parte infine costituita dalla traduzione dei Tombeaux con testo a fronte.

3 Vari e interessanti sono gli aspetti di questo complesso volume che riaccende i riflettori su un autore a lungo dimenticato e che solo nel 1995 ha visto rinnovarsi l'interesse per 
le sue opere. Intendiamoci: non siamo di fronte a un grandissimo della storia teatrale del Settecento; è pur tuttavia vero che Mercier è autore geniale e che la critica non gli ha reso forse il giusto omaggio. Ai suoi tempi le sue stravaganze e le sue prese di posizione originali non gli hanno permesso di godere di quella fama cui aspirava. E tuttavia alcune idee di Mercier sono assolutamente innovative per l'epoca e rispecchiano la formidabile ascesa della borghesia e degli ideali di cui era portatrice. Interessanti sono, ad esempio, le sue aperture agli strati più poveri della popolazione, la sua apologia del lavoro e del risparmio, che lo avvicina a un altro importante autore dell'epoca, ancora oggi poco noto: Michel Jean Sedaine. Per quanto attiene ai Tombeaux de Vérone, Ligas sostiene che la pièce non è un'imitazione diretta di Romeo and Juliet, come vorrebbe la tradizione ma è invece il risultato di influenze più complesse che passano per gli adattamenti di Christian Felix Weisse (1768) e di Ozincourt (1771). Solo indirettamente quindi Mercier si sarebbe ispirato alla pièce di Shakespeare. A questa conclusione Ligas giunge dopo un'analisi attenta e approfondita dell'opera di Mercier, basandosi in particolare sul "taglio massonico" della pièce che sembra caricare i Tombeaux di una forte simbologia, tesa a esaltare più gli ideali di amicizia, di amore e di libertà che a costruire il dramma secondo le innovative idee espresse dallo stesso Mercier nel suo Du Théâtre ou Nouvel essai sur l'art dramatique del 1773. I Tombeaux de Vérone si distinguono dal resto della produzione di Mercier sia dal punto di vista tecnico (rispettano per esempio le tre unità), sia soprattutto dal punto di vista linguistico. Questo sembra essere in effetti l'aspetto più interessante. Ligas giunge alla conclusione che le scelte lessicali di Mercier evidenziano forti analogie con il «vocabulaire maçonnique» e che partecipano all'evocazione di simboli e rituali massonici. Il linguaggio della massoneria, che nel Settecento è il linguaggio della Rivoluzione, è ampiamente utilizzato da Juliette, la vera protagonista della pièce, ma anche da Roméo, che pure ha un ruolo marginale. Termini importanti del vocabolario massonico, quali uguaglianza, libertà, giustizia, sensibilità, ricorrono continuamente nei Tombeaux, unitamente a inequivocabili situazioni iniziatiche. Il lavoro si chiude con la traduzione (ad opera dello stesso Ligas) dei Tombeaux de Vérone. Una traduzione con testo a fronte che utilizza l'edizione del 1784, e per redigere la quale l'A. si avvale anche di dizionari bilingui del Seicento e del Settecento. Importante e lodevole è senz'altro l'imponente apparato di note che correda sia il testo francese, sia il testo italiano. In conclusione un prezioso lavoro cui potranno utilmente attingere letterati e linguisti. 